\title{
The Platform Function of Macao in the Foreign Investment of Chinese Mainland Enterprises
}

\author{
Xuyang DONG \\ The Institute for Social and Cultural Research (ISCR), Macau University of Science and Technology
}

\begin{abstract}
Chinese mainland enterprises generally set "interlayer" companies within the framework of foreign investment to reduce the risk in foreign exchange, taxation, financing and other aspects. This paper has discussed about the platform function of Macao in the foreign investment of mainland enterprises through analyzing the advantages of the Macao Special Administrative Region in terms of system, culture, financial service, setup, operation cost, tax system and other aspects. This paper has drawn the following conclusions through investigation method and qualitative analysis method: in case that the mainland enterprises want to invest in Portuguesespeaking countries that have signed bilateral tax agreement with Macao, Macao is undoubtedly an ideal area for setting "interlayer" companies. In case that the final investment destination is non-Portuguese-speaking countries, although the advantages for setting "interlayer" companies in Macao will be greatly reduced, it can still exert functions such as the isolation of investment risk, the deduction of tax, etc. to some extent. Most previous relevant researches has focused on "tax avoidance heaven", such as Hong Kong Region of China, and Cayman Islands; while the innovative point of this paper is to mainly discuss about the platform function of Macao Region in the foreign investment of mainland enterprises that are neglected by researchers, but possess an important investment strategy position.
\end{abstract}

Keywords-Macao; Mainland enterprises; Foreign investment; Investment framework; "Interlayer" companies

\section{INTRODUCTION}

Recently, one of the important measures of our country for opening has been implementing "the strategy of enterprises going out", i.e., through foreign investment, labor service cooperation, engineering contracting and other modes, actively participate in the international cooperation and competition. This measure is quite meaningful for the sustainable economic development in our country and the exploitation of foreign market. In 2013, when General Secretary Jinping XI visited Central Asia and Southeast Asia, he respectively put forward the cooperation initiative of constructing "New Silk Road
Economic Belt" and "21st Century Marine Silk Road" (hereinafter referred to as "The Belt and Road"). ${ }^{1}$ Up till May, 2017, 66 countries had participated in the construction of "the Belt and Road" in total, and the total population and economic aggregate were respectively about 4.4 billion and USD 22 trillion, which respectively occupied about $63 \%$ and $30 \%$ worldwide, and the industrial structure complementarity for countries along the line was strong, making it the economic belt with the most development potential. ${ }^{2}$ The construction of "The Belt and Road" is an important strategic decision made by the party central committee, and also an important measure for our country to implement the new round of expanded opening.

The main objective of "The Belt and Road" is to realize the trade and investment contacts between China and countries along the line. Of which foreign investment is the main aspect. It is of great significance for Chinese enterprises to conduct foreign investment in solving the excessive industry of our country, promoting scientific and technical progress, exploiting resource channel, realizing sustainable development strategy and other aspects.

\section{MAIN MODE OF FOREIGN INVESTMENT FOR CHINESE ENTERPRISES AND THE NECESSITY FOR SETTING "INTERLAYER" \\ COMPANIES}

Foreign investment mainly includes two modes, i.e., greenbelt investment and the merger and acquisition of enterprises. Greenbelt investment refers to setting new whollyowned or joint venture company abroad, which can contribute to the enterprises in controlling foreign investment cost, and realizing true technical innovation, etc. The merger and acquisition of enterprises refer to the acquisition or merger of all or partial equities in overseas target enterprises, to realize the objective of foreign investment. The merger and acquisition of enterprises can contribute to enterprises in avoiding the entrance of barriers, obtaining synergistic effect, decreasing competition and reinforcing the market control, etc. Since 2012 our country's direct investment impetus for the world has been fast, as shown in Figure 1.

${ }^{1}$ People.com.cn: Correctly understand "The Belt and Road" http://theory.people.com.cn/n1/2018/0226/c40531-29834263.html

${ }^{2}$ Kui DAI (2017) Development Opportunities of Macao under the Construction Background of "The Belt and Road". Modernized Management Period 12, 2017, 33-35. 


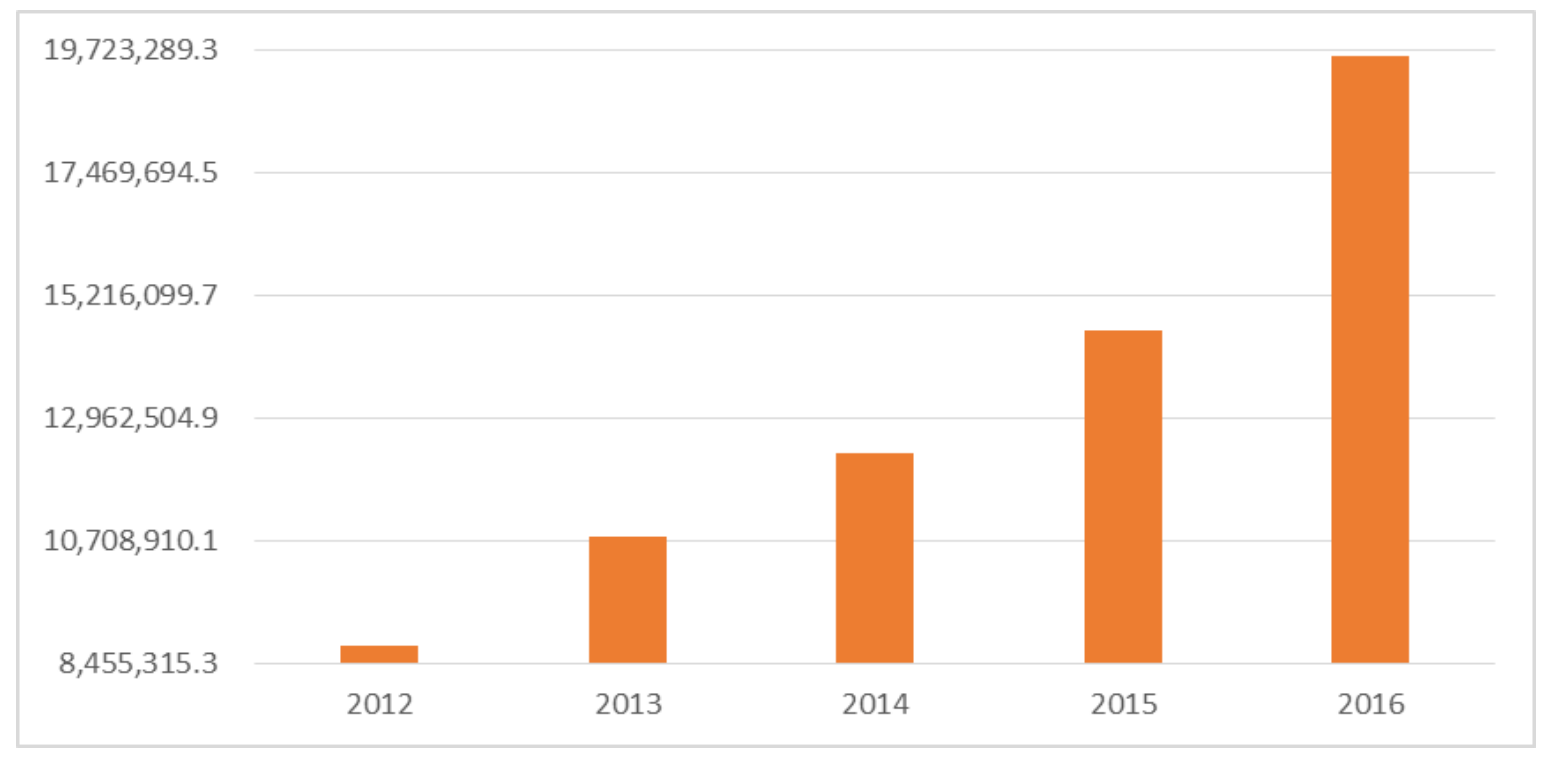

Fig. 1. The Trend Chart about the Net Amount of Chinese Direct Investment to the World from 2012 to 2016 (ten thousand dollars)

As for the holding structure, enterprises going out can adopt direct holding or multi-layer platform of indirect holding mode. The mode adopted by enterprises for the investment shall generally combine the economic development level of the host country, the scale of investment industry, the technical level, management and other aspects of factors. In consideration of the current regulation in foreign exchange, tax, financing and other aspects in the mainland of China, many enterprises will set "interlayer" companies in the framework of foreign investment to restrict the aforementioned negative factors to the largest extent. As for the foreign exchange, the mainland of China is the region that hasn't realized the free exchange freedom yet, and currently, it still implement a tougher foreign exchange regulation policy; As for the tax, in case that the income tax rate for the investment destination is relatively high, foreign investment enterprises shall often consider setting "interlayer" companies at transit countries or regions that have low tax, massive tax protocol network and can fully enjoy tax preference treatment, and hold the overseas entities; As for the financing policies, since the setup and supervision for financial enterprises are quite strict in the mainland, financing difficulty is a very common phenomenon, through setting "interlayer" companies at regions with relatively convenient financing, and this can be quite beneficial to the fund flow of foreign investment for the entire corporate group.

The setup of "interlayer" companies can contribute to enterprises in the isolation of operational and legal risks during the process of foreign investment, and can also improve the financing convenience and validly decrease the foreign investment tax of enterprises. Investment destination, the tax policy of the motherland and the management measures can be directly related to the foreign investment return level of enterprises, and most enterprises going out need to decrease or defer taxes via tax planning. Make plans for single or several "interlayers" meeting the condition, on one hand, expand the

${ }^{3}$ Implementation of "One-country, Two-system" in Hong Kong Special Administrative Region White Paper

http://www.scio.gov.cn/ztk/dtzt/2014/31039/31042/Document/1372893/13728 93.htm. a. (Official website of National Bureau of Statistics)

b. http://data.stats.gov.cn/easyquery.htm?cn=C01 \&zb=A060G01 \&sj=2016 offset scope, on the other hand, improve the introduction of other investors and the flexibility of equity transfer. Of course, the cost for setting and maintaining "interlayer" companies, such as the registered capital for companies in the country or the region, the requirements about the quantity of local directors, the expenses and time for setup, the annual audit requirements, etc., The foreign exchange management conditions in the country or region, the financial business conditions, international reputation, etc. Are also called as the factors that shall be mainly considered in the selecting the place to set "interlayer" companies.

\section{THE StRAtegic Position OF MACAO IN THE ForeigN} INVESTMENT OF CHINESE MAINLAND ENTERPRISES--ANALYSIS ON THE ADVANTAGES AND DISADVANTAGES AS "INTERLAYER" COMPANIES

In practice, through making comprehensive balance from investment policies, foreign exchange policies, tax system and other factors, the ideal choice for setting "interlayer" companies is in Hong Kong of China, British Virgin Islands (BVI), Cayman Islands, Dubai and other countries and regions. However, along with the layout development of GuangdongHong Kong-Macao Greater Bay Area, Macao Special Administrative Region across the sea of Hong Kong Special Administrative Region has presented several advantages in system, culture, financial service, setup, operation cost, tax system and other aspects, and is now increasingly become an important "port" for Chinese mainland enterprises to invest in Portuguese-speaking countries during the process of "going out". 


\section{A. System Advantages}

Just like Hong Kong, Macao has the unique advantages of "one-country, two-system" of our country. "One-country, twosystem" is the abbreviation for "one country, and two systems". "One-country, two-system" refers to the mainland adhering to regarding the socialist system as the subject of the entire country, and meanwhile, permitting Taiwan, Hong Kong, and Macao to preserve the capitalism system. ${ }^{3}$ The maintaining of capitalism means that Macao can continuously implement free port system and independent tax right. According to the relevant regulations stipulated in The Basic Law of the Macao Special Administrative Region, Macao still enjoys independent legislative right, judicial right and administrative management right. Chinese mainland enterprises choose to set "interlayer" companies at Macao, so when being compared with setting "interlayer" companies in the surrounding other countries or regions along "The Belt and Road", it can better enjoy the convenience brought by "one-country, two-system". In 2003, the mainland and Macao Special Administrative Region Government signed the arrangement of The Mainland and Macao about Establishing Closer Economic and Trade Relations (i.e., "CEPA" Agreement) and then signed the Supplementary Agreement, Supplementary Agreement II, and Supplementary Agreement III in 2004, 2005, and 2006 respectively CEPA Agreement is the successful practice of our country to carry forward "one-country and two-system" system, the new route for the mainland and Macao to conduct institutional cooperation, and an important milestone for the economic and trade exchange and cooperation between the mainland and Macao Region. CEPA Agreement is the free trade agreement signed between the subject of our country and Macao Separate Customs Territory, and is also the first free trade agreement comprehensively implemented in the mainland.

\section{B. Cultural Fusion Advantages}

Macao is the place that blends Chinese and western trade, and business; meanwhile, it is also the place that blends Chinese and western cultures. Especially for Portuguesespeaking countries, after a long-term development over the history, Macao has become the city that blends Chinese and western culture. Such cultural blending advantages are quite important for setting "interlayer" companies, and can contribute to the promotion of cultural adaptation for transnational corporations; it belongs to a kind of imitable and irreplaceable resources in Macao, and can be hard to be imitated by other countries or regions.

On the other hand, Macao has lots of overseas Chinese. They are closely combined via families, the association of fellow townsmen and other forms of associations. These associations and organizations have certain influence in the economic development of the Macao local regions and countries along "The Belt and Road". Such associations can promote the non=governmental exchange between Macao and "the Belt and Road" countries.

${ }^{4}$ Data source: Official website of Macao International Trade Investment Expo: http://www.mif.com.mo/mif2015/about_macau.php

${ }^{5}$ Macao Daily News Macao creates a Portuguese-speaking RMB liquidation platform (November 25, 2014)

http://www.boc.cn/aboutboc/ab8/201411/t20141126_4211035.html

${ }^{6}$ Qingyang WANG. [Taxes for Going out] Transfer to Macao for Foreign Investment: Why Not to Make Interlayer Companies More Practical. China

Taxation News, 2017.9.1

\section{Financial Services Advantages}

The financial services of Macao have many competitive advantages.

Firstly, the financial industry in Macao is stable and normalized. In each global economic crisis, the bank industry in Macao has shown excellent performance in risk management, validly resisted each economic crisis, and the financial industry can always keep a stable trend.

Secondly, the financial industry in Macao has the congenial conditions for providing financial services for transnational companies. Macao has been keeping trade relations with above 100 countries and regions worldwide, and is also the member of above 50 international organizations. ${ }^{4}$ As for the business operation, Macao and the international conventions can adapt to each other, with convenient and transparent investment business environment, and foreign enterprises can enjoy national treatment. All of these conditions have made clients of the financial industry in Macao enjoy a globalized treatment in the scope of financial service.

Thirdly, Macao plays the role of RMB primary clearing bank. Along with the reform of interest rate liberalization, the freely convertible capital project and other financial fields being accelerated in China, RMB will have a wide international development space. Being benefited from the acceleration of the RMB international development process, the bank circle in Macao has kept the stably increased development trend of RMB business. Over above ten years, the bank industry in Macao has fully utilized the platform advantages of Macao and carried out closer cooperation with the same industry in Portuguese-speaking countries, and has been engaged in creating the liquidation center for China and Portuguesespeaking countries, and meanwhile, providing safe, qualified and high-efficient financial services for clients in China and Portuguese-speaking countries ${ }^{5}$.

The professionalization and internationalization of financial service in Macao can provide financial assurance for Chinese mainland enterprises setting foreign investment "interlayer" enterprises in Macao.

\section{The Setup Procedures are Simple for "Interlayer" Companies with Low Operational Cost}

The laws or administrative procedures for overseas and local individuals or institutions that plan to set companies in Macao are the same. Investors can handle all the procedures for setting companies via Macao Trade and Investment Promotion Institute's investor "one-stop" service, and the notary agency's [company (corporate business owners) setup and registration one-stop service] or lawyers. The procedures are relatively simple, and the registration efficiency is relatively high.

In practice, in order to control the operational cost of foreign investment, many Chinese mainland enterprises don't want to input too many substantial capitals in "interlayer" companies after the setup; besides, they merely use the lowest operational cost to maintain the company as the cost to invest "interlayer" companies. In this respect, Macao still has bigger low operational cost advantages. Macao is close to Zhuhai, but Zhuhai has a relatively cheap price, and convenient traffic, so 
Macao enterprises have the opportunity to configure corresponding assets from the mainland with lower cost. Besides, Macao Special Administrative Region Government will also launch series of support plan in finance, and decrease the enterprise site rents and other operational costs.

Although Macao Special Administrative Region is a society with high welfare, the occupation tax and social insurance related expenses borne by employees and employers are the lowest among the mainland, Hong Kong Special Administrative Region, Macao Special Administrative Region and Taiwan Region. This characteristic can largely decrease the human resource cost for Chinese enterprises to erect "interlayer" companies in Macao ${ }^{6}$.

TABLE I. TRIAl BALANCE FOR Human Resource Costs

Assuming that the monthly salary is MOP 40,000

\section{Difference}

Individual income

Macao residents

Actual tax bearing rate: $1.2 \%$

$\operatorname{tax}$

\section{Social security \\ contributions}

Totally MOP 90 with the employer
Non-Macao residents

Tax bearing rate: $3 \%$
Totally MOP 200 with the employer
Since certain foreign investment project is often quite long in time span, and can reach to several years and even decades, the advantage of low operational cost will be expanded by the time span.

\section{E. Simple Tax System and Low Tax Rate}

Generally speaking, Macao belongs to regions with lower tax rate. Macao Region regards income source place as the tax governance principle, with simple tax system, low and stable tax rate; for a long time, it is one of the places with the lowest tax rate among Asian countries and regions, and is also the famous "tax haven" in Asia.

The Macao region has simple taxation and non-repetitive taxations. The type of taxes in Macao mainly includes the income tax supplementary, business tax, and occupation tax. The income tax supplementary belongs to progressive tax, and the tax rate is $3 \%-12 \%$. Of which, people whose income tax payables reach to above MOP 300,000 , the tax rate is $12 \%$; people whose income tax payables reach to above MOP 32,000, the payment obligation of this type of tax can be exempted. The business tax shall be decided by the operational industry engaged by enterprises. The tax amount for general industries is within the range of MOP 150-1,500, and the tax amount for most forestry and animal husbandry, manufacturing industry, chemical industry, wholesale, retail, and business service industry is MOP 300. The occupation tax in Macao is also progressive tax. The tax rate is $7 \%-12 \%$. The individual's tax exemption limit is MOP 95,000. The aforementioned advantages in tax system have made Macao more attractive than other "The Belt and Road" countries and other countries and regions in the investment of Chinese mainland enterprises, and can better play the role of "interlayer" companies in the foreign investment framework of Chinese enterprises.

\section{F. Lower Commercial Essence Requirements}

Whether "interlayer" companies can meet commercial essence is quite important for designing foreign investment framework. Whether the "interlayer" company of one enterprise has commercial essence is the important basis for the tax authority to judge whether the enterprise is classified as conduit companies, and further judge whether the enterprise can enjoy the tax agreement preferential treatment. Meanwhile, if "interlayer" companies don't have commercial essence, the tax authority may start anti-tax avoidance investigation about the tax authorities, and increase tax risks. In the past, the "interlayer" structure set by enterprises via foreign investment is mostly reflected as the shell company without substantial operation or management activities, and many countries or regions with lower tax rate also permit and even encourage the existence of shell companies. Since OECD published BEPS Action Plan (note: BEPS: tax base erosion and profit transfer) in 2013, all counties and regions, including the "tax avoidance heaven" have reinforced the economic and commercial essence requirements for resident enterprises.

The so-called "interlayer" companies for enterprises shall have commercial essence, i.e., it requests that the company shall have the assets, personnel and operational activities matching its profits, practically play necessary operation or management roles, rather than merely performing the registration. The configuration of assets, personnel and relevant operational activities will correspondingly generate operational cost. Decreasing this part of cost to the minimum is an important thing that shall be considered for selecting "interlayer" companies. As mentioned before, Macao Region is relatively convenient considering the traffic and customs clearance with the mainland, which has made "interlayer" companies configure corresponding assets, personnel and carry 
out relevant operational activities at a lower cost in Macao Region, and these corresponding assets, personnel and relevant operational activities can exactly cope with the investigation and requirements of tax authority considering commercial essence.

The advantages for selecting Macao as the ideal region for mainland enterprises to set "interlayer" companies for foreign investment have been elaborated from different layers mentioned above. But risks and opportunities coexist, domestic enterprises mainly have the following disadvantages in conducting foreign investment via Macao.

Firstly, as the place of registration for "interlayer" companies, the main disadvantage of Macao is few tax agreement with other countries and regions. As per the authorization of the Central Government (and the SinoPortugal Joint Liaison Group during the transition period), the Special Administrative Region has carried out negotiations with relevant target countries, and concluded several agreements, up till the end of 2017, the office had assisted in authorizing the Special Administrative Region to sign tax information exchange or double taxation avoidance agreement with 27 countries, including Denmark, and Australia ${ }^{7}$. Macao Region shall actively learn from the experience of international tax coordination, base on the essential point of ensuring the tax profits of the Special Administrative Region, actively comply with the trend of regional tax coordination, make preparations, respond actively, and work hard to sign tax information exchange or double taxation avoidance agreement with more countries or regions.

Secondly, under the influence of historical reasons, the gambling industry has occupied a crucial economic position in the economy of Macao Region. This characteristic has caused the simple economic structure in Macao Region, and then made it weak in resisting economic risks. Macao Region shall closely seize the opportunities brought by the construction of "The Belt and Road", and then on the basis of ensuring the characteristic industry of gambling industry, constantly promote its own economic diversity and reinforce its capacity to resist economic risks.

\section{SUMMARY}

Along with the promotion of "The Belt and Road", the foreign investment steps for Chinese mainland enterprises have become increasingly firm. During foreign investment, Chinese mainland enterprises can realize it via greenbelt investment or merger mode. However, no matter which mode is adopted to realize foreign investment, it is very important and necessary to erect "interlayer" companies in the overall investment framework.

Due to historical reasons, in case that the mainland enterprises want to invest in Portuguese-speaking countries that have signed bilateral tax agreement with Macao, Macao is undoubtedly an ideal area for setting "interlayer" companies. In case that the final investment destination is non-Portuguesespeaking countries, although the advantages for setting "interlayer" companies in Macao will be greatly reduced, it can still exert functions such as the isolation of investment risk, the deduction of tax, etc. to some extent. Along with the construction of "one center, one platform and one base", Macao is expected to become the destination for setting "interlayer" companies held by mainland enterprises within a wider foreign investment field, and exert the function of platform in the foreign investment of Chinese mainland enterprises.

\section{REFERENCES}

[1] Zhiwei AN. Optimization Scheme Design for the Foreign Investment Framework erection of Chinese Enterprises [J]. Trade and Economic Accounting, 2017.5: 15-20

[2] Yuan CHEN. The Role of Hong Kong in the Strategy of "Going out"[J] Chinese Economic Annual Conference, 2011-2012:8-9

[3] Kui DAI. Development Opportunities of Macao under the Construction Background of "the Belt and Road"[J] Modern Management Science, 2017, 12: 33-35

[4] Jiuwen SUN and Honggui PAN. "The Belt and Road" Strategic Positioning and Macao Opportunities [J]. Modern Management Science, 2016, 1:27-29

[5] Qingyang WANG. [Taxes for Going out] Transfer to Macao for Foreign Investment: Why Not to Make Interlayer Companies More Practical [N]. China Taxation News, 2017.9.1

[6] Qingyang WANG. Research about the Bilateral Tax System in Macao [M] Macao: Press of Macao University of Science and Technology, 2010.12

[7] Bin XIA. Political Suggestions for Using Hong Kong Platform to Promote the Foreign Investment of Chinese Enterprises [J]. Journal of Chongqing Institute of Technology, 2009.3:1-4

[8] Yuncheng ZHANG. Role and Function of Hong Kong In the Strategy of "Going Out" for the New Era of China [J]. Modernized International Relationship, 2011.8:15
${ }^{7}$ Official website of the Office of The Commissioner of The Ministry of Foreign Affairs of The People's Republic of China in The Macao Special Administrative Region

http://www.fmcoprc.gov.mo/chn/satfygjzz/tyyflsw/amtq/t241604.htm. 